\title{
Crustal structure over the Nagssugtoqidian deformation front in West Greenland: Receiver Function analysis
}

\author{
Trine Dahl-Jensen, Peter H. Voss and Tine B. Larsen
}

A marked change in crustal thickness is seen at the deformation boundary between the undisturbed Archaean core in the south and reworked Archaean gneiss in the foreland of the Nagssugtoqidian orogen in West Greenland. In addition, intra-crustal boundaries can be tentatively interpreted. This is the first information on crustal structure in the area, which is known for kimberlite, carbonatite and ultramafic lamprophyre occurrences, and diamond exploration.

The information is based on two summer seasons of passive seismological data - earthquakes - recorded on five broadband seismological stations placed on an almost 200 $\mathrm{km}$ long profile crossing the deformation boundary. The stations were installed in the remote area with solar panels and batteries. Between 11 and 27 distant earthquakes were recorded on each of the five stations used for the Receiver Function analysis.

\section{Geological background}

The Receiver Function profile (Fig. 1) is located on Precambrian rocks in Central West Greenland. It crosses over a deformation front marking the southern Nagssugtioqidian front defined by the transition from undeformed, discordant dykes in the south to extensively deformed dykes in the southern Nagssugtoqidian orogen in the north. Between the Inland Ice and Sukkertoppen ice cap this front is marked by a sharp change in aeromagnetic signatures (van Gool et al. 2002). The structural front coincides with a metamorphic transition and marks the southernmost boundary of penetrative Palaeoproterozoic reworking at amphibolite facies. There is a continuity of lithologies across the southern Nagssugtoqidian front, and reverse, south-directed thrusting shows that the southern Nagssugtoqidian orogen is a parautochthonous foreland belt (van Gool et al. 2002).
Fig. 1. Geological map of the area (Henriksen et al. 2009). The location of the deformation front is based on aeromagnetic data (Rasmussen $\&$ van Gool 2000). The stations used are indicated by a blue star. The station SFJD was not used.

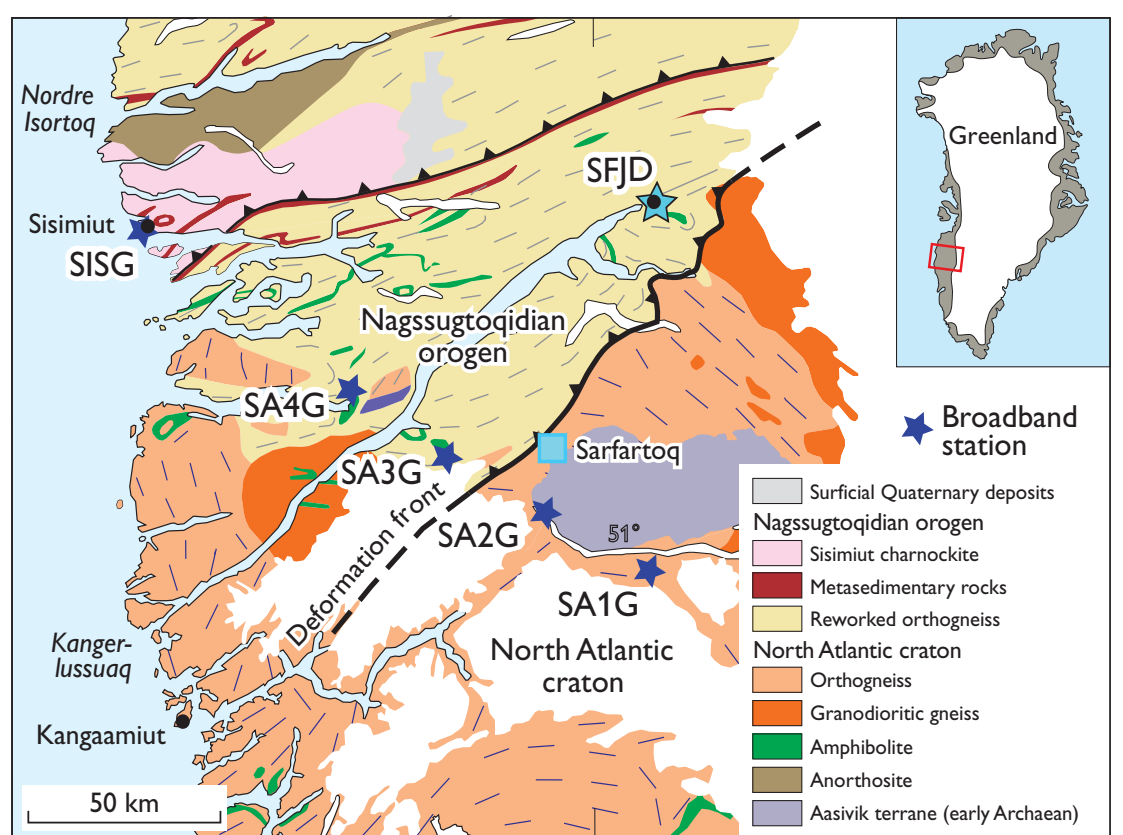



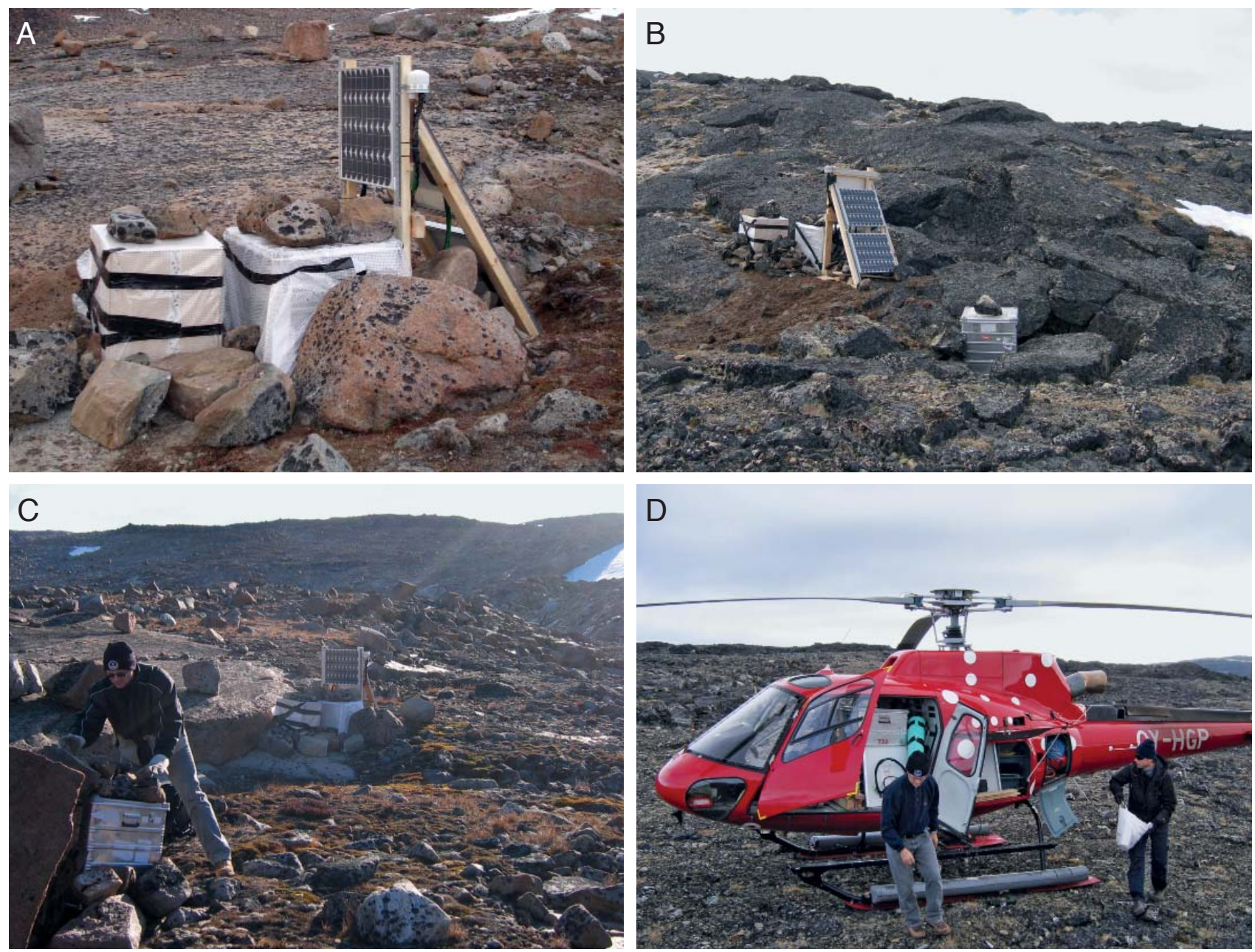

Fig. 2. The seismic stations. The almost $100 \%$ exposure of bedrock allows for all stations to be placed on hard rock. A: SA1G. The completed installation in 2006 with solar panels facing south, the sensor placed on bedrock and insulated, and just as the datalogger, protected against the elements. Photo: K.K Sand. B: SA2G was installed in 2006. Photo: P.H.Voss. C: SA4G packed in 2007 for return. Photo: H. Rasmussen. D: From SA3G. The seismic stations were deployed and returned by an Air Greenland AS350. Photo: H. Rasmussen.

\section{Data and method}

Receiver Function (RF) analysis relies on recording naturally occurring earthquakes followed by the isolation of S-waves generated locally at geological boundaries under the recording station from incoming P-waves from distant earthquakes (Ammon 1991).

\section{Data acquisition}

To acquire data, five seismometer stations were installed along a profile with c. $34 \mathrm{~km}$ distance (Fig. 1). Four of the stations where located in the wilderness (Fig. 2), and one in the town of Sisimiut. The stations were equipped with Güralp-3T broadband 3-component sensors and 24 bit SAM data loggers, recording data locally. The stations recorded data from June 2006 to early September 2007.
Power was supplied by batteries, charged by solar panels. Consequently the stations did not record in November, December and January when the lack of sunlight prohibited charging the batteries. For each station, teleseismic events were selected in several steps. Lists of events over magnitude 5.0 were generated from international earthquake catalogues (USGS 2015), and useable events were selected by individual inspection of the recorded waveforms. The noise conditions varied from station to station.. In total, 41 individual earthquakes (Fig. 3) were accepted for analysis on one or more of the five stations, resulting in 95 earthquake records for RF analysis. The number of accepted records varied from 11 to 27 on the individual stations. The events range from magnitude 5.3 to 8.3 and cover a large azimuth and distance range around Sarfartoq. 


\section{Method}

For each of the records the RF was calculated (Kind et al. 1995; Yuan et al. 1997). First, a bandpass filter of 2-50 sec $(0.5-0.02 \mathrm{~Hz})$ was applied. Then the $P$ phases were rotated in three dimensions to minimise early energy on the radial and transverse components. This procedure aligns one component $(\mathrm{L})$ with the incoming $\mathrm{P}$ energy, one $(\mathrm{Q})$ with the SV energy and one (T) with SH energy. The energy from the P-S converted phases should then be isolated on the $\mathrm{Q}$ component, and the $\mathrm{T}$ component should not contain any energy if the structure beneath the station is horizontally stratified. The obtained inclination and azimuth were compared to the theoretical values calculated using the IASP91 model (Kennett \& Engdahl 1991), and events discarded if the inclination differed by more than around $5^{\circ}$ and azimuth by more than $10-15^{\circ}$. The Q component was then deconvolved with the $\mathrm{L}$ component (Ammon 1991) to produce the 95 receiver functions (RFs). The final step is to depth-convert and back-trace each RF in $3 \mathrm{D}$ in the earth and project the data onto a profile following the method described in (Yuan et al. 1997).

\section{Results}

Figure 4 shows the back-traced receiver functions from each station along the profile. The RFs overlap more and more with depth, providing a complete cover at $c .50 \mathrm{~km}$ depth for the four inland stations where the distance between stations is $c .34 \mathrm{~km}$. The Mohorovicic discontinuity (Moho) is clearly seen, as well as some indications of intracrustal boundaries. The frequency content of the RF is low $(0.5-0.02 \mathrm{~Hz})$ so we cannot expect to resolve structural details. The depth to Moho varies from just under $40 \mathrm{~km}$ at the SE (inland) end of the profile to just under $50 \mathrm{~km}$ at the NW end, which lies offshore. The change of depth to Moho appears as a slope dipping $18^{\circ}$ towards NW in the plane of the profile, starting at the location where the profile crosses the deformation front, and thus at the sharp boundary seen on the aeromagnetic data (Rasmussen $\&$ van Gool 2000; van Gool et al. 2002). The crustal thickness at Kangerlussuaq (SFJD, Fig. 1) is $47 \mathrm{~km}$ (Dahl-Jensen et al. 2003), correlating well with the thickness along the profile NW of the deformation zone. South of the deformation front, the shallower Moho also is in agreement with thinner crust reported in the Archaean block in South Greenland (Dahl-Jensen et al. 2003). The slope on Moho starts directly underneath the location of the deformation front on the surface, indicating that the deformation front is fairly steep. The intra-crustal boundaries are poorly defined, due to the relatively large distance between the sta-

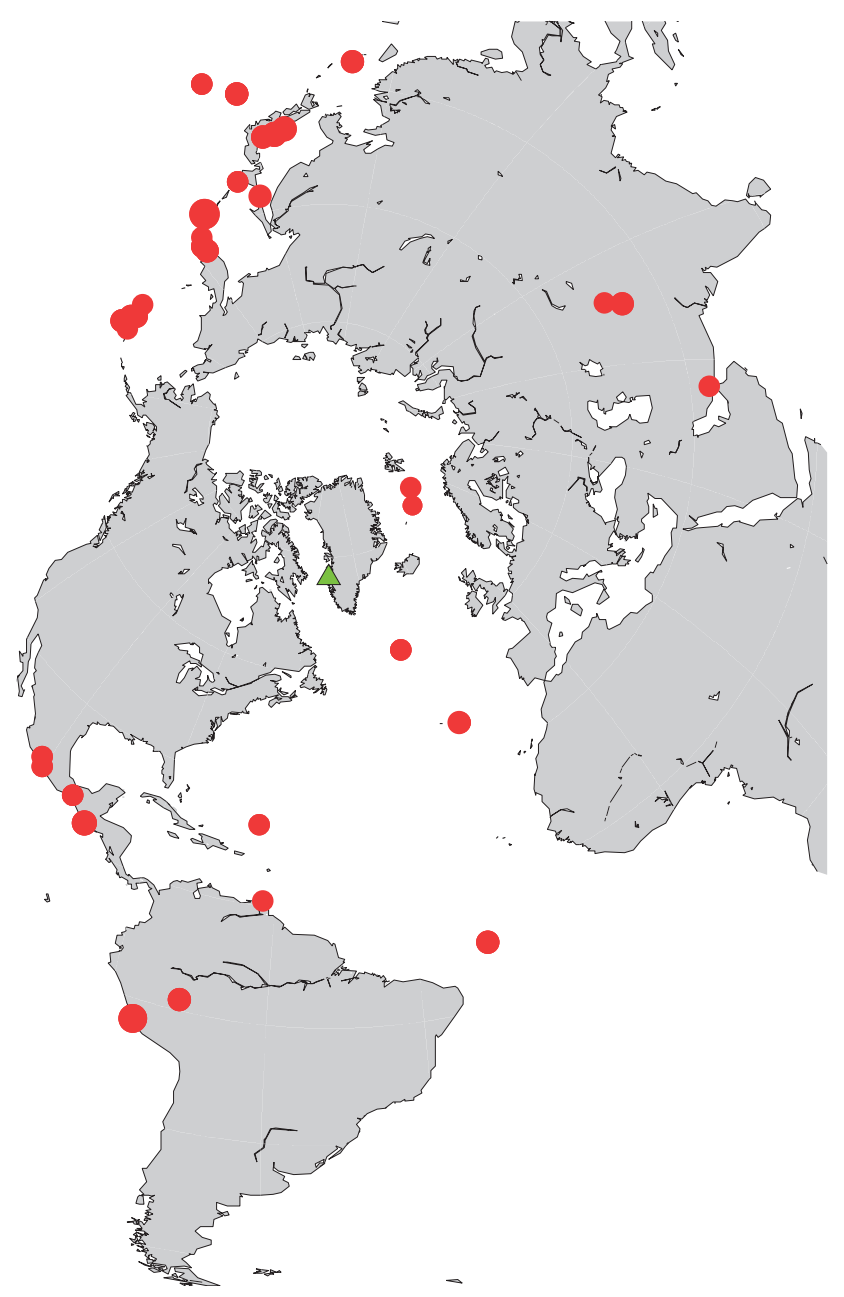

Fig. 3. In all, 41 events were selected for RF analysis recorded on one or several of the five stations on the profile (green triangle). The events (red dots) are scaled by magnitude, ranging from 5.3 to 8.3 .

tions, but all indicate a dip towards NW, mimicking the slope on the Moho. To the SE of the deformation front the intracrustal converters seem weaker, possibly indicating the more undisturbed Archaean rocks of the North Atlantic craton.

\section{Evaluation and outlook}

This study illustrates that recording distant earthquakes over a period of several months, along a profile of seismological sensors can be utilised to image local, large-scale structures, which are valuable in areas where active source seismic acquisition is very costly. The profiles obtained can provide information on crustal thickness and intra-crustal structure. Higher resolution images than available in this study can be obtained if station spacing is smaller. RFs also 


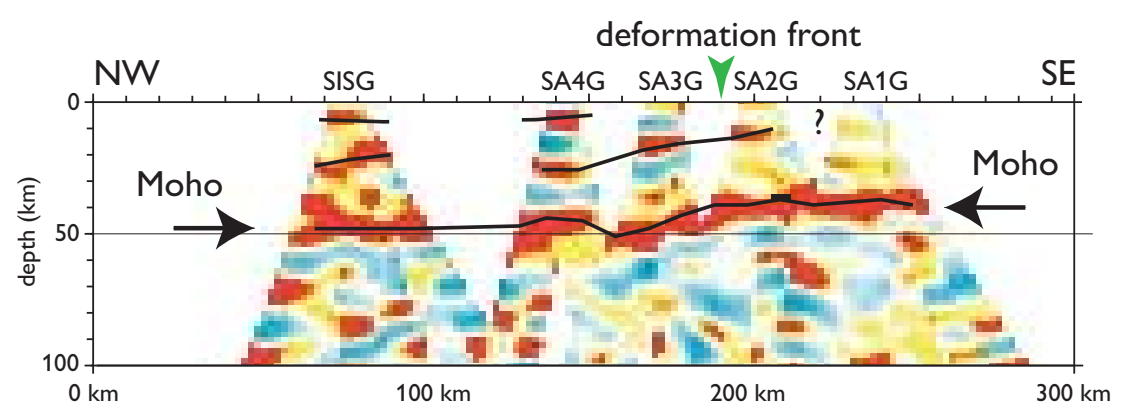

Fig. 4. The profile is scaled 1:1 horizontally and vertically; no vertical exaggeration. Red colour marks a conversion at an interface with higher impedance below the boundary (increasing velocity and density with depth). Under each station the backtraced traces from the individual RF derived from different earthquakes can be seen as a cone, overlapping more with depth. The interpretation of Moho and intra-crustal converters are marked with a thin black line. allow mapping of deeper structures in the mantle. The study area is an exploration area for diamonds (Tappe et al. 2011), and information on the lithosphere will contribute to the understanding of the generation of diamond-bearing formations. A next step will be to look for converted phases from the base of the lithosphere. These are expected to have a negative polarity as the velocities are expected to drop at the transition from the lithosphere into the asthenosphere. For example, in East Greenland a similar profile outlined a fossil subduction zone (Schiffer et al. 2014).

\section{Acknowledgements}

SeisUK at University of Leicester lent us the instruments for data collection. The Ministry of Mineral Resources, Greenland, provided the funds for the installation, operation and recovery of the stations in Greenland.

\section{References}

Ammon, C.J. 1991: The isolation of receiver effects from teleseismic P-waveforms. Bulletin of the Seismological Society of America 81(6), 2504-2510.

Dahl-Jensen, T., Larsen, T.B., Woelbern, I., Bach, T., Hanka, W., Kind, R., Gregersen, S., Mosegaard, K., Voss, P. \& Gudmundson, O. 2003: Depth to Moho in Greenland: receiver-function analysis suggests two Proterozoic blocks in Greenland. Earth and Planetary Science Letters 205(3-4), 379-393.

Henriksen, N., Higgins, A.K., Kalsbeek, F. \& Pulvertaft, T.C.R. 2009: Greenland from Archaean to Quaternary. Descriptive text to the 1995 Geological map of Greenland, 1:2 500 000. 2nd edition. Geological Survey of Denmark and Greenland Bulletin 18, 126 pp.
Kennett, B.L.N. \& Engdahl, E.R. 1991: Traveltimes for global earthquake location and phase identification. Geophysical Journal International 105(2), 429-465.

Kind, R., Kosarev, G.L. \& Petersen, N.V. 1995: Receiver functions at the stations of the German Regional Seismic Network (GRSN). Geophysical Journal International 121(1), 191-202.

Rasmussen, T.M. \& van Gool, J.A. 2000: Aeromagnetic survey in southern West Greenland: project Aeromag 1999. In: Dawes, P.R. \& Higgins, A.K. (eds): Review of Greenland activities 1999. Geology of Greenland Survey Bulletin 186, 73-77.

Schiffer, C., Balling, N., Jacobsen, B.H., Stephenson, R.A. \& Nielsen, S.B. 2014: Seismological evidence for a fossil subduction zone in the East Greenland Caledonides. Geology 42(4), 311-314.

Tappe, S., Pearson, D.G., Nowell, G., Nielsen, T., Milstead, P. \& Muehlenbachs, K. 2011: A fresh isotopic look at Greenland kimberlites: Cratonic mantle lithosphere imprint on deep source signal. Earth and Planetary Science Letters 305(1-2), 235-248.

USGS 2015: National Earthquake Information Center - NEIC. http:// earthquake.usgs.gov/earthquakes/?source=sitenav: United States Geological Survey.

van Gool, J.A.M., Connelly, J.N., Marker, M. \& Mengel, F.C. 2002: The Nagssugtoqidian Orogen of West Greenland: tectonic evolution and regional correlations from a West Greenland perspective. Canadian Journal of Earth Sciences 39, 665-686.

Yuan, X., Ni, J., Kind, R., Mechie, J. \& Sandvol, E. 1997: Lithospheric and upper mantle structure of southern Tibet from a seismological passive source experiment. Journal of Geophysical Research 102(B12), 27491-27500. 